\title{
RESEÑA: ESTUDIO DE LAS FORMAS DE TRATAMIENTO Y DE LA CORTESÍA EN LA NOVELA GONE WITH THE WIND, DE MARGARET MITCHELL. MARÍA ROSA CABELLOS CASTILLA*
}

\author{
Juan José Lanero Fernández** \\ María Rosa Cabellos Castilla 2005. Estudio de las formas de tratamiento y de la \\ cortesía en la novela Gone with the Wind, de Margaret Mitchell. Universidad de Alcalá, \\ 208 págs. ISBN 84-8138-640-5.
}

Asomarse al trabajo de la Dra. Cabellos Castilla es un acto que necesita poco esfuerzo. Y por varias razones: la primera, porque su estudio tiene una motivación social. Y tómese el término en el sentido de sociedad y en el concreto que la sociolingüística le concede. Varias son las generaciones que han visto, y vuelto a ver, lo que el doblaje nos ha presentado en español bajo el nombre de Lo que el viento se llevó. Pocos -cierto es-, son los que identifican película-novela-autora. Como fenómeno social es casi lo de menos. Esta película/novela, y seguro que por este orden, pertenece a lo cotidiano de nuestras vidas. Scarlet O'Hara es citada en conversaciones de plaza y de café.

Desde el punto de vista literario, varios personajes han cobrado vida propia. Viven en la mente de todos. Ese asociacionismo de filmografía-literatura-costumbres resulta ser un fenómeno no muchas veces repetido a lo largo de la historia reciente. ¡Y qué decir de la música que acompaña a los sucesos! Es un hecho que, de una forma o de otra, todos tenemos un momento de nuestras vidas vinculado, sobre todo, a la película. Por lo tanto, la elección de la novela para realizar un estudio de las formas de tratamiento y de la cortesía es absolutamente apropiada.

Pero, lo mismo que algunas escuelas de crítica literaria nos enseñan que hay varios niveles o escalas para la lectura de una obra, aquí nos encontramos con la segunda razón que nos despierta el interés por el libro de la Dra. Cabellos Castilla: la escala superior de la lectura, el análisis de la novela pero desde una perspectiva en la que confluyen la sociolingüística, la pragmática y la valoración literaria. Las tres se entremezclan y conceden una visión mucho más clara, nítida y fija que la que nos podría dar, únicamente, cualquiera de ellas.

Fecha de recepción: octubre 2006

Fecha de aceptación y versión final: octubre 2006

*** Profesor titular, Departamento de Filología Moderna, Universidad de León; $\square$ dfmjlf@unileon.es. 
La obra está divida en dos partes. En la primera, la Dra. Cabellos Castilla recorre las teorías de tratamiento y de la cortesía. Va desgranando los estudios iniciados por Brown y Gilman (1960) y, después de analizar las formas de tratamiento en el inglés americano, se introduce en los estudios sobre la cortesía. Se nos disculpará si destacamos, sobre todo, la teoría de Brown y Levinson (1987). Estos autores destacan que la elección de la estrategia de cortesía viene determinada por consideraciones de poder, distancia y grado de imposición. Poder, para influir en las acciones de otra persona; distancia, para marcar la cercanía o lejanía que sentimos hacia los demás; y la imposición, referida al esfuerzo que el individuo tiene que realizar para hacer o rechazar algo. En un estudio breve, publicado hace algún tiempo en Odisea (Lanero, 2001), aplicamos la teoría de Brown y Levinson a la negociación en el mundo de la empresa y de los negocios. Sencillamente: nos encontramos ante una teoría que, lo mismo que es aplicable para lograr un acuerdo entre representantes de compañías, encuentra su hueco vital para definir el tipo de relación social que se da entre dos personajes de una novela. De ahí que deba afirmarse que la autora de este estudio ha sabido elegir un prisma apropiado para un análisis más completo de la novela. Fundamentalmente, porque lo que arroja luz sobre actitudes y comportamientos sociales en la novela, también previene al lector ante un determinado uso de la cortesía verbal que, sin dejar de serlo, puede ser de naturaleza positiva o negativa.

\section{III}

En la segunda parte del estudio, María Rosa Cabellos entrelaza un recorrido biográfico por la vida de Margaret Mitchell con la recepción de la obra. El concepto de recepción, que cada vez se maneja con mayor intensidad en los estudios de traducción, se utiliza aquí desde la atención que le dedicaron los lectores y la crítica y de los que arrancó opiniones contrapuestas. Resulta obvio que la novela no ha ingresado en el canon literario norteamericano. Y es difícil que lo haga. Aunque esta frase sea mera especulación. A nuestro modo de ver, varias son, entre otras, las causas: el tratamiento del momento histórico, de tanta relevancia para el pueblo americano en general, y del Sur en particular, sirve de mera excusa para situar, en tiempo y lugar, el desarrollo de la acción; el fenómeno del Sur, con sus creencias y convicciones, queda relegado a un elemento decorativo; y el delicado, a la vez que controvertido, tema del racismo, son despachados por encima. Estos tres aspectos bordean la novela, pero Mitchell no les concede, a pesar de que la merecen, una atención especial. Uno se pregunta, pues, como lo hace Cabellos Castilla, haciendo un recorrido de la crítica literaria existente, dónde y cómo pueden unirse los conceptos de popularidad y de calidad literaria, que no son necesariamente excluyentes. Los tiempos se encargarán, sobre todo el literario, de situar a esta novela en el lugar que le corresponde. Por nuestra parte pensamos que, por su impacto, es un buen ejemplo para utilizar a la hora de reflexionar y sacar conclusiones para la teoría literaria.

En los capítulos en los que se estudia la relación entre Scarlett O'Hara y los principales personajes de la novela (Rhett Butler, Melanie Wilkes, Ashley Wilkes) y entre Rhett Butler y Melanie Wilkes, Cabellos Castilla aplica un mismo patrón de análisis cifrado en

Odisea, $\mathrm{n}^{\circ}$ 7, ISSN 1578-3820, 2006, 229-231 
tres puntos que encuentran su base en la exposición teórica de la primera parte: evolución de la relación entre personajes; uso de las formas de tratamiento y uso de las estrategias de cortesía. El resultado es la relación social que se establece entre los personajes; la naturaleza de la misma, cómo discurre y evoluciona.

Con este enfoque la autora sustancia cómo se materializa en el uso de la lengua clase social, dominio, poder, fortaleza, abuso, igualdad, superioridad, sumisión.... Aspectos que ofrecen una radiografía clara y nítida de la relación que se mantiene entre los dos personajes que cada capítulo aborda.

\section{IV}

Este análisis sociolingüístico y pragmático de Gone with the Wind logra desentrañar las relaciones sociales entre los principales personajes de la novela. Nos encontramos ante un estudio novedoso. Novedoso y afortunado en la elección del corpus que analiza. Presenta en su discurso cómo funcionan unas herramientas útiles para medir cómo en el uso de la lengua se refleja la identidad del personaje, su extracción social, sus fines y objetivos y lo que pretende mediante la estrategia que utiliza con quien conversa; sea altanera, cercana, distante, franca, aduladora, conquistadora o receptiva. Es la condensación social en el vocabulario y en las estructuras retóricas que utilizan los personajes. Es llegar a la posibilidad de medir el ser y el estar.

En definitiva: este estudio nos presenta un nuevo modo de hacer la valoración de una obra literaria. Su estructura presenta un modelo que puede seguirse en textos literarios canónicos, no canónicos y aún en otros ámbitos textuales. Por lo que hace a la novela de Margaret Mitchell, es capaz de presentarnos una conclusión no sólo valiosa sino indispensable para una comprensión íntegra: substanciar en el tratamiento y en la cortesía sentimientos, deferencias, posturas y deseos que, con un análisis literario puro, puede que deduzcamos o adivinemos, pero que son difíciles de demostrar y recoger. María Rosa Cabellos nos presenta multitud de ejemplos palmarios en su trabajo, con el que el lector disfruta en su lectura, y lentamente nos va introduciendo en una dimensión importante de la obra literaria: la relación social concretizada en la elección de palabras y en la cortesía que dispensamos o negamos a los demás.

\section{REFERENCIAS}

Brown, P. and S. C. Levinson 1987. Politeness: Some Universals in Language Use. Cambridge University Press.

LANERO, J.J. 2001. “Apuntes sobre el arte de la negociación: interculturalidad y cortesía en el inglés empresarial”. Odisea, vol. 1, pp. 131-137. 